\title{
Factors influencing the trust-level of Hungarian negotiators in cross-cultural business contexts
}

\author{
Júlia Szóke \\ Department of International Studies and Communication \\ Széchenyi István University, Győr, Hungary
}

\section{Keywords}

Business, cross-cultural contexts, Hungarian negotiators, trust

\begin{abstract}
Trust is considered to be an essential element of effective business relationships. However, it is not easy to build trust as it varies from culture to culture which aspects influence trust-level. Therefore, this paper discusses the importance of trust in cross-cultural business contexts from the viewpoint of Hungarian negotiators, using data deriving from a two-phase research. In the first phase of the research, a questionnaire survey was used to assess the importance of trust in cross-cultural business contexts, and then structured interviews were conducted to reveal the factors influencing the level of trust. The findings provide insights about the role of trust as well as the factors affecting it in cross-cultural business contexts to shed light on the possible consequences of the low level of trust to business success. The paper also draws up some conclusions and recommendations in general as well as for representatives of companies doing business with Hungarian partners.
\end{abstract}

\section{Acknowledgment}

This paper is sponsored by NTP-NFTÖ-19 programme supported by the Ministry of Human Capacities of Hungary.

\section{Introduction}

The past decades have seen the globalization of business environment. This has induced the increasing number of business relations between partners coming from different countries and cultures. As a result of this, considerable attention has been focused recently on the investigation of cross-cultural business activities (e.g. Ablonczy-Mihályka, 2014 and 2015; Adler and Aycan, 2018; Adler and Graham, 2017; Merkin, 2017; Szóke, 2013; Tompos, 2015), especially negotiations (e.g. Caputo et al., 2019; Dinkevych et al., 2017; Nádai, 2017; Peleckis et al., 2015). In spite of this, there are still some certain aspects of the research into cross-cultural business activities which have remained less explored, especially in Hungary and from a Hungarian viewpoint. One of these aspects is related to trust, i.e. the factors affecting it, the consequences of the lack of it, and its positive effect(s) on cross-cultural business relations.

Therefore, the present paper sets out to examine trust and the factors influencing it in cross-cultural business contexts. In particular, it aims to reveal the factors that affect the trust-level of Hungarian business actors when negotiating with foreign partners, which provides the originality of the paper. The rationale behind the investigation is the growing number of cross-cultural business activities involving Hungary, which necessitates business actors who are able to work with partners whose cultural background is different. However, doing business with foreigners is not easy as besides business aspects, social, political, and cultural ones must be considered as well. As a consequence of these, trust has been considered an important factor when doing cross-cultural business. Furthermore, according to Covey (2006), trust is the one thing that changes everything, as he points out, low trust is the greatest cost in life and in organizations since it creates inter alia interpersonal conflict, win-lose thinking, defensive and protective communication.

The first part of the paper gives a brief overview of trust in general and the factors that may influence it. The second part discusses the methods and results of the research examining the factors that affect the trust-level of Hungarian negotiators in cross-cultural business contexts. The research to be discussed in this paper was a two-phase one, thus both the findings of the quantitative part and those of the qualitative part are introduced. Finally, the paper draws up some conclusions related to the factors affecting the trust-level of Hungarian negotiators and makes some recommendations for both the 
Hungarian negotiators and the representatives of companies doing business with Hungarian partners so that the relations could be more effective and the occurring negative effects of the low trust-level could be avoided.

\section{Literature review}

Trust is a well-researched concept at international level, since researchers in all parts of the world have been investigating the concept of trust for more decades (e.g. Covey, 2006; Doney et al., 1998; Fukuyama, 1995), but it is less explored in Hungary. In highlighting the importance of trust, it is inevitable to mention that trust is a complex, multifaceted concept with many interpretations.

According to The Explanatory Dictionary of the Hungarian Language, trust is one's feeling towards someone whose honesty, resistance, good abilities, intentions, and helpfulness one is persuaded of (Bárczi and Országh, 1962). Similarly, Cummings and Bromiley (1996, p. 303) state that trust is nothing else than "an individual's or group's belief that another individual or group makes efforts to uphold commitments, is honest, and does not take advantage given the opportunity". An analogous, but broader definition was drawn up by Ring and Van de Ven (1992), who identified trust as the reaction of an individual to subjective uncertainty regarding the behavior of the interaction partner. This concept includes expected as well as uncertain, and thus feared behavior of the partner. According to another concept, trust is a belief or confidence that one party has about another party's characteristics that may increase willingness to take risks and ultimately help "solve" the social dilemma (Ferrin et al., 2007).

Based on the above definitions, it is obvious that trust is an issue that may be approached from different viewpoints and can be defined in several ways. Yet two basic views of the concept of trust can be distinguished, i.e. the faith-based and the risk-based ones, which is reflected by the aforementioned definitions. These two aspects do not contradict each other; however, they focus on diverse issues. According to the faith-based approach, the source of trust is the partners' faith in each other, thus the partners put faith in each other's reliability and honesty (Kumar, 1996). Based on this approach, trust is the sum of belief and expectations, and the intention of the partners to behave as expected (Doney et al., 1998). On the contrary, according to the risk-based view, trust is a positive perception of the partner's behavior in such a way that the partner does not act in an opportunist way in case of any change of circumstances (Das and Teng, 2004). Thus, trust means that partners voluntarily take risks despite they become vulnerable to the other. This notion is closely related to the theory of transaction costs (Coase, 1937). Factors belonging to transaction costs and influencing trust are relation-specific investments, behavioral uncertainty/replaceability, and exchange of information. Nevertheless, there are some other factors that have influence on trust like, for instance, the perceived conflict, the perceived satisfaction, and the business partner's reputation. These factors derive from social exchange theory, according to which every human relation is determined by the analysis of contributions and advantages (Thibaut and Kelley, 1959).

Regarding the factors that can lead to trust (or distrust) in general, numerous, and sometimes overlapping examples can be found in literature. Out of these, Adler (2001) emphasizes the following three factors: familiarity through repeated interaction, calculations based on interests, and values and norms that create predictability and trustworthiness. Besides these, there are, of course, other factors which may influence trust like direct interpersonal contact, reputation, honesty, competence, loyalty, openness (Adler, 2001), communication (Thomas et al., 2009), emotional bonding (Eberl, 2004), stereotypes (Peleckis et al., 2015), and cultural differences (e.g. Finuras, 2019; Fukuyama, 1995).

Despite the diversity of concepts and influencing factors, researchers agree that trust is an essential element of effective business relationships and can facilitate business relations because one who believes the partner is trustworthy will develop a higher willingness to risk. It is particularly true when business takes place between partners with different cultural backgrounds. Hofstede (1991) states that culture is nothing else than the mental programming of the mind, therefore different cultures perceive business relations in different ways. This idea is supported by more researchers (e.g. Aulakh and Kotabe, 1996; Doney et al., 1998; Finuras, 2019) who also assume that trust in business relations correlates with national culture. Other researchers (e.g. Hall, 1995; Håkansson and Snehota, 1995) even go beyond this as they state that national culture determines the relationships as well as those behavioral factors that affect the 
evolution and the level of trust. Consequently, the factors influencing the development and the level of trust vary from culture to culture.

\section{Research methodology}

Based on the above, the purpose of this paper is to discuss the importance of trust in cross-cultural business contexts from the viewpoint of Hungarian negotiators as well as to reveal the factors influencing their trust-level to determine which factors affect mostly the trust-level, and which ones decrease it so that the potential consequences of the low level of trust could be illustrated. Considering that the research investigates cross-cultural business relations, its assumption is that it is mostly the cultural stereotypes that influence the trust-level of Hungarian negotiators. Consequently, the research to be discussed in this paper was a two-phase research using different methods. In the first phase a quantitative research was carried out to assess, inter alia, the importance of trust in cross-cultural business contexts as well as to find out about the factors influencing the level of trust. This survey was a joint work of the author with a colleague, and some partial results have already been published, but from aspects other than trust (cf. Kecskés, 2019; Szőke, 2019). In the second phase a qualitative research was conducted by the author on her own to reveal, in more details, those factors that influence trust and to investigate which factors increase and which ones decrease the level of trust so that more accurate conclusions could be drawn regarding the effect of these factors on trust as well as on the relation itself. Nevertheless, the present paper discusses only those factors that decrease trust-level to shed light on the possible consequences of the low level of trust to business success. Besides trust, the qualitative research involved the role of stereotypes in building and developing trust, however, it is not a topic to be discussed in the present paper.

The quantitative part of this research is based on a survey carried out in Hungary among Hungarian business actors frequently working and communicating with partners coming from different cultures. The questionnaire was online and self-administered, and convenience sampling was used to recruit respondents, therefore the findings of the research cannot be applied to the whole population, i.e. all Hungarian business actors frequently involved in foreign business relations. The questionnaire investigated the role of stereotypes and trust in corporate relations, consequently it was divided into four parts out of which one contained demographic questions, one referred to the company of the respondent, one investigated trust, and another one examined the role of stereotypes in corporate relations. Among the questions there were rating questions (by means of 5-point scales), close-ended and open-ended ones. The analysis of the responses was carried out by means of descriptive statistics excluding multivariate regression analysis. A total of 204 questionnaires were filled out, however, after data cleansing the responses of 124 could be examined. The respondents' demographic data are as follows: the questionnaire was filled out by 75 male and 49 female respondents. 15 subjects stated they are in upper managerial positions, 18 are middle managers and 91 are employees. 72 out of the 124 respondents are younger than 35, 49 are aged between 36 and 55, and 3 are older than 55. As for qualifications, 102 respondents hold a bachelor's or master's degree, 21 did not take part in tertiary studies, whereas one subject has PhD.

The qualitative part of the research is based on structured interviews conducted among some of the respondents of the quantitative part of the research. The interviewees were selected by snowball method, so first the interviewees were selected from the author's own network, and then other interviewees were 'snowballed' by the firstly selected subjects. As a result of this method, a total of 33 interviews were conducted. The content of the interviews was examined by the methods of meaning coding, meaning condensation, and meaning interpretation, as described by Kvale (1996). As for the demographic data of the interviewees, it can be said that there were 21 female and 12 male subjects. Three claimed they are in upper managerial positions, 6 are middle managers and 24 are employees. As for age, 18 interviewees are younger than 35, 15 are aged between 36 and 55, and none of them is older than 55. All but one interviewee finished their tertiary studies.

\section{Findings}

The present paper discusses some results of the third part of the questionnaire survey and those findings of the qualitative research that are related to trust and the factors decreasing its level. Firstly, the importance of trust is introduced from the viewpoint of the subjects, then the factors influencing the trustlevel of the respondent Hungarian business negotiators are demonstrated, and finally, the factors 
decreasing the level of trust are examined to shed light on the consequences these factors might have with regard to the relation.

The questionnaire survey sought for information about the importance of trust in cross-cultural business contexts and found out that trust is seen as a very important factor of business relations, according to the subjects. Some respondents even went beyond that by stating that trust is not only very important, but, in fact, a key element. The respondents were also invited to tell what trust means to them with the help of an open-ended question. The most common responses included mutual confidence, reliability, fairness, commitment, and unconditional, honest communication. The data deriving from the structured interviews confirm these ideas since none of the interviewees believe that trust is of less importance. In answering the question referring to the meaning of trust, obviously, notions similar to those of the quantitative research were mentioned. It was found out that for the majority of the interviewees (85\%) trust means reliability, however, honest communication (36\%) was also turned out to be an important element of trust for them. Besides these, cooperation, predictability, fairness, responsibility, loyalty, mutuality, less risk, and even punctuality of payment was reported by the interviewees. In general, the responses given suggest that the respondent Hungarian negotiators perceive trust from its faith-based view seeing that trust is equivalent to reliability from their viewpoint. Nevertheless, a few responses (e.g. less risk) were related to the risk-based view of trust.

To determine the factors influencing the trust-level of the respondents, 16 items in the form of attitude statements were used in the questionnaire. Five-point scales (1: fully disagree, 2: disagree, 3 : neither agree nor disagree, 4: agree, 5: fully agree) were applied to measure the items. Analyzing the responses given, it turned out that it is the communication between the partners (mean: 4.62; standard deviation: 0.57) that exerts the greatest influence on the level of trust, after that the duration of the relationship (mean: 4.32; standard deviation: 0.74), and then the frequency of contacts (mean: 4.17; standard deviation: 0.84). These suggest that the style, frequency, and honesty of communication positively affect the development of trust as well as its level. On the other hand, it seems that the more lasting and frequent the relations are, the more the respondents trust their foreign partner. The factors that exert the least influence on the trust-level were found to be the prejudices related to the partner's country (mean: 2.87; standard deviation: 1.04), the negative stereotypes known about the partner's country (mean: 2.95; standard deviation: 1.07), and the positive stereotypes known about the partner's country (mean: 3.14; standard deviation: 1.04). Considering that the standard deviation was high in each case, the median was also examined and proved to be 3 in each case. These results indicate that the respondents are divided from the viewpoint of the influencing role of stereotypes. It is also demonstrated by the fact that $34.7 \%$ of the subjects agreed to some extent with the influencing role of positive stereotypes, whereas $30.7 \%$ agreed somewhat with that of negative stereotypes. As for prejudices, $27.4 \%$ agreed to some extent that they have an impact on trust. In view of these findings, it is of particular interest which factors influence trust in general, according to the respondents of the qualitative research.

For the present purposes, the responses given to this question were coded and categorized so that they could be compared to those of the questionnaire survey. As a result of this method, the factors that influence the level of trust the most were revealed to be as follows, in order of their importance: previous experience, reliability, stereotypes, news and rumors about the given country/company, the duration of the relationship, and common goals and values. Nevertheless, a few interviewees believe that cultural differences, nationality, reputation, the partner's personality, cooperation, helpfulness, flexibility, openness, and the first impression also pertain to the influencing factors in general. When comparing the findings of the quantitative analysis with those of the qualitative one, it can be seen that the influencing factors are to some extent different, especially if it is taken into consideration that honest communication, which is considered to be the most important factor by the respondents of the questionnaire survey, was not even mentioned by the interviewees. Furthermore, the only factor that was mentioned in both phases of the research is the duration of the relationship. Another interesting result is related to stereotypes which are seen as the least important factor by the respondents of the first research phase, but according to the interviewees, these pertain to the most influencing ones. However, it is sufficient to point out that respondents, in the first phase of the research, were asked to evaluate predetermined alternatives, whereas they responded freely to an open-ended question in the second phase, which may contribute to 
these differences. Nevertheless, when the interviewees were invited to talk about those factors that influence their trust-level in case of cross-cultural business contexts, slightly different results were found again. The vast majority of them $(91 \%)$ stated that previous experiences is the factor that influences them the most. Besides this, communication, reliability, the duration of the relationship, personal acquaintanceship, and stereotypes are those factors that have an impact on the trust-level of a relatively high rate of the subjects. Consequently, it can be concluded, in spite of the differences in the data stemming from the two phases of the research, that the subjects attribute the greatest influencing role to factors related somehow to the relationship itself, i.e. previous experiences, honest communication with the partner, the duration of the relationship, the partner's reliability, and the frequency of contacts. Nevertheless, the effect of stereotypes on trust are not negligible either as the findings, especially those of the second phase indicate it.

To determine the potential consequences of the low level of trust, it was also investigated, within the frames of the interviews, which factors decrease the trust-level of the subjects. It turned out that it is mostly the previous negative experiences (e.g. unkept promises, mistakes, lies, insolvency) that decrease the level of trust. Nevertheless, inappropriate communication, stereotypes, and the lack of experience were also mentioned as important trust-decreasing factors by most of the interviewees. Nationality, prejudices, envy, and jealousy were found to decrease the level of trust only in case of a few interviewees. Based on these results, it can be assumed that if the level of trust is low because of the previous negative experiences, especially those ones mentioned by the interviewees, it can lead to negative consequences like a more formal regulation of the relationship to avoid uncertainty, or even the discontinuation of the relationships. The trust-decreasing effect of inappropriate communication may result in more common misunderstandings or defensive communication, which can further decrease the level of trust generating this way a vicious cycle. Stereotypes, once again, were found to be of importance, however, in this case from a negative viewpoint, as it seems that negative stereotypes tend to decrease the trust-level of the interviewees, which may lead to changed behavior and attitude towards the foreign business partner. Based on these results, it can be stated that cultural stereotypes do have an impact on trust, although not to the greatest extent.

\section{Discussions and conclusions}

The present paper investigated the factors influencing the trust-level of Hungarian business negotiators in cross-cultural business contexts. First, secondary research was conducted, and the importance of trust in business relationships was studied. Having reviewed the literature of trust, it was found out that trust is a concept that is well-researched worldwide but is less explored in Hungary and from a Hungarian aspect. Literature review involved the concept of trust as well as the factors influencing it in general. A relationship between cultural differences and trust was also found, therefore, conducting primary research on the factors influencing the trust-level of business actors of a certain nation/culture is proved to be of importance. As a consequence of the aforementioned, an empirical research into the influencing factors of Hungarian negotiators' trust-level in cross-cultural business contexts is novel and provides the originality of the present paper.

The research presented in this paper had two phases. At first a quantitative survey was conducted, and then a qualitative one. The research findings show that trust is important for the respondent Hungarian negotiators in case of their cross-cultural business relationships. It was also found that the majority of the respondents perceive trust from its faith-based view considering that they interpret trust as reliability, and only a few of them perceive trust from its risk-based view. In analyzing the factors influencing the trust-level of the respondents, interesting, but sometimes contradictory results were found. On the one hand, it was revealed that in general previous experiences, reliability, and stereotypes affect trust, according to the respondents. On the other hand, in connection with the factors that influence the subjects' trust-level, factors related to the relationship itself (e.g. previous experiences, honest communication, reliability, and the duration of the relationship) were found to have the greatest influence, and interestingly, stereotypes were identified as less influencing factors, despite it was among the top three contributors to trust in general, according to the respondents. These findings show that, in contrast with the assumption of the paper, it is not the stereotypes that affect the trust-level of the respondent Hungarian negotiators the most. Therefore, the assumption is rejected. Yet, it must be 
mentioned that even though they are not the most influencing factors, their relevance is unquestionable since a significant number of the subjects attach importance to them. It was also investigated which factors decrease the level of trust to shed light on the possible consequences of the low level of trust. It turned out that previous negative experiences, improper communication, and stereotypes (obviously negative ones) influence the trust-level of the respondents in a negative way. These suggest that the possible outcomes of the low trust-level include more regulated relationships to avoid further negative experiences as well as uncertain and feared situations, more misunderstandings and protective communication as a result of inappropriate communication, and even changed behavior and attitude towards the foreign business partner caused by stereotypes.

Based on the research findings, it can be concluded that it is the factors related to the relationship itself that have the greatest influence on the trust-level of the respondent Hungarian negotiators. Nevertheless, stereotypes are of importance as well. Therefore, on the one hand, it is recommended that, as Tompos (2014) states, Hungarian business professionals should know and use stereotypes accurately to understand the different perspectives of the foreign partner which could help avoid a decrease in the level of trust and reach business success. On the other hand, it is suggested for those foreigners who do business with Hungarians that they should be aware of the fact that stereotypes sometimes affect their Hungarian partner's attitude, so they should act upon with this end in view. Furthermore, both the Hungarian and the foreign business actors are recommended to keep in mind that trust is a mutual concept, thus everyone should be trustworthy, communicate honestly, and try to avoid mistakes to have successful and lasting business relationships.

\section{Limitations and direction for future research}

This paper, of course, is not without any limitations. First of all, the review of literature has been limited to only those sources which are closely related to the present topic; therefore, it is believed that future works should include more sources with diverse aspects. The inclusion of sources with other viewpoints would shed more light on the factors influencing trust-level other than those discussed in the present paper. Secondly, the quantitative survey, by being online and self-administered, and the convenience sampling together resulted in a low number of respondents, which did not allow for drawing general conclusions referring to the population. Even though no other sampling method seemed to be appropriate due to the willingness of individuals to take part in surveys, future works should try to apply another method to increase the sample size. The same applies to the qualitative research, i.e. the number of interviewees should be increased to get a broader picture about the factors influencing trust. Lastly, for the purposes of the present paper, descriptive statistics were used by means of linear regression, however, in the future multivariate regression analysis should be conducted to investigate the correlations between the variables and to be able to study the concept of trust in a deeper and broader aspect. This leads us to one of the future directions of the research, i.e. to carry out multivariate regression analysis. Another direction should focus on the differences in trust-level related to the country of origin of the foreign business partner. In connection with that the research should investigate, on the one hand, whether Hungarians trust some nations, cultures easier or better than others, and if yes, what is the reason for this. On the other hand, it may as well be investigated whether trust-level is influenced by different factors depending on the partner's country of origin.

\section{References}

Ablonczy-Mihályka, L. (2014). When in Rome Do as the Romans Do: Is It a Reality of Business Life? In: Proceedings of the 14th International Academic Conference. [online] Prague: International Institute of Social and Economic Sciences (IISES), pp. 1-9. Available at: https://iises.net/proceedings/14th-international-academic-conferencemalta/table-of-content/detail?article=when-in-rome-do-as-the-romans-do-is-it-a-reality-of-business-life[Accessed 23 Nov. 2019]

Ablonczy-Mihályka, L. (2015). Cross-Cultural Communication Breakdowns: Case Studies from the Field of Intercultural Management. In: Proceedings of the $18^{\text {th }}$ International Academic Conference. [online] Prague: International Institute of Social and Economic Sciences (IISES), pp. 22-32. Available at: https:/ /iises.net/proceedings/18th-international-academic-conference-london/table-ofcontent $/$ detail ?article $=$ cultural-communication-breakdowns-case-studies-from-the-field-of-interculturalmanagement [Accessed 24 Nov. 2019] 
Adler, N. and Aycan, Z. (2018). Cross-Cultural Interaction: What We Know and What We Need to Know? Annual Review of Organizational Psychology and Organizational Behavior, 5, pp. 307-333.

Adler, N. and Graham, J. (2017). Cross-Cultural Interaction: The International Comparison Fallacy? In: Language in International Business. JIBS Special Collections. Cham: Palgrave MacMillan, pp. 33-58.

Adler, P. (2001). Market, Hierarchy, and Trust: The Knowledge Economy and the Future of Capitalism. Organization Science, 12(2), pp. 215-234.

Aulakh, P. and Kotabe, M. (1996). Trust and Performance in Cross-Border Marketing Partnerships: A Behavioural Approach. Journal of International Business Studies, 27(5), pp. 1005-1032.

Bárczi, G. and Országh, L. (1962). The Explanatory Dictionary of the Hungarian Language. (A magyar nyelv értelmezó szótára). Budapest: Akadémiai Kiadó.

Caputo, A., Ayoko, O., Amoo, N. and Menke, C. (2019). The Relationship Between Cultural Values, Cultural Intelligence and Negotiation Styles. Journal of Business Research, 99, pp. 23-36.

Coase, R. (1937). The Nature of the Firm. Economica, 4(16), pp. 386-405.

Covey, S. (2006). The Speed of Trust. New York: Free Press.

Cummings, L. and Bromiley, P. (1996). The Organizational Trust Inventory (OTI): Development and Validation. In: R. Kramer and T. Tyler, eds., Trust in Organizations: Frontiers of Theory and Research. Thousand Oaks, CA: Sage Publications, pp. 302-330.

Das, T. and Teng, B.-S. (2004). The Risk-based View of Trust: A Conceptual Framework. Journal of Business and Psychology, 19(1), pp. 85-119.

Dinkevych, E., Wilken, R., Aykac, T., Jacob, F. and Prime, N. (2017). Can Outnumbered Negotiators Succeed? The Case of Intercultural Business Negotiations. International Business Review, 26(3), pp. 592-603.

Doney, P., Cannon, J. and Mullan, M. (1998). Understanding the influence of national culture on the development of trust. Academy of Management Review, 23(3), pp. 601-620.

Eberl, P. (2004). The Development of Trust and Implications for Organizational Design: A Game- and AttributionTheoretical Framework. Schmalenbach Business Review, 56(3), pp. 258-273.

Ferrin, D., Bligh, M. and Kohles, J. (2007). Can I Trust You to Trust Me? A Theory of Trust, Monitoring, and Cooperation in Interpersonal and Intergroup Relationships. Group E Organization Management, 32(4), pp. 465499.

Finuras, P. (2019). Culture Differences and Trust. Journal of Intercultural Management and Ethics, 4, pp. 5-12.

Fukuyama, F. (1995). Trust: The Social Virtues and the Creation of Prosperity. New York: Free Press.

Hall, W. (1995). Managing Cultures: Making Strategic Relationships Work. Chichester: Wiley.

Håkansson, H. and Snehota, I. (1995). Developing Relationships in Business Networks. London: Routledge.

Hofstede, G. (1991). Cultures and Organizations: Software of the Mind. London: McGraw-Hill.

Kecskés, P. (2019). The Study of Cultural Proximity's Impact on Inter-Organizational Relations. (A kulturális közelség szerepének tanulmányozása a vállalatközi kapcsolatokban.) In: Cultural Economy: Gyula Kautz Memorial Conference (Kulturális gazdaság: Kautz Gyula Emlékkonferencia). [online] Győr: Széchenyi István Egyetem Kautz Gyula Gazdaságtudományi Kar, p. 8. Available at:

https://kgk.sze.hu/images/dokumentumok/kautzkiadvany2018/Kecsk\%C3\%A9s\%20Petra_Kautz_2018_Tan ulm\% C3\% A1ny.pdf [Accessed 10 Feb. 2020]

Kumar, N. (1996). The Power of Trust in Manufacturer-Retailer Relationships. Harvard Business Review, 74(6), pp. 93107.

Kvale, S. (1996). InterViews: An Introduction to Qualitative Research Interviewing. Thousand Oaks, CA: Sage Publications.

Merkin, R. (2017). Saving Face in Business: Managing Cross-Cultural Interactions. New York: Springer.

Nádai, J. (2017). Stereotypes: An obstacle or trigger to business success? European Journal of Sustainable Development, 6(1), pp. 174-180.

Peleckis, K., Peleckiené, V. and Peleckis, K. (2015). Trust Building Problems in Business Negotiations and Business Meetings: Interference, Stereotypes, Trust Substitutes. Journal of Management Policies and Practices, 3(2), pp. 5159.

Ring, P. and Van de Ven, A. (1992). Structuring Cooperative Relationships Between Organizations. Strategic Management Journal, 13(7), pp. 483-498.

Szőke, J. (2013). Managing Cultural Differences When Doing Business Internationally. International Journal of Business and Management Studies, 2(2), pp. 349-357.

Szőke, J. (2019). Business communication in view of cultural stereotypes. (Üzleti kommunikáció a kulturális sztereotípiák tükrében.) In: Cultural Economy: Gyula Kautz Memorial Conference (Kulturális gazdaság: Kautz Gyula Emlékkonferencia). [online] Győr: Széchenyi István Egyetem Kautz Gyula Gazdaságtudományi Kar, p. 8. Available at:

https://kgk.sze.hu/images/dokumentumok/kautzkiadvany2018/Sz\%C5\%91ke\%20J\%C3\%BAlia_Kautz_2018_Tanul m\%C3\%A1ny.pdf [Accessed 10 Feb. 2020] 
Thibaut, J. and Kelley, H. (1959). The Social Psychology of Groups. New York: Wiley.

Thomas, G., Zolin, R. and Hartman, J. (2009). The Central Role of Communication in Developing Trust and Its Effect on Employee Involvement. International Journal of Business Communication, 46(3), pp. 287-310.

Tompos, A. (2014). How Stories Contribute to a Deeper Understanding of Cultures Introductions. Sociokulturnyje Problemy Jazyka I Kommunikacii: Sbornik Naucnych Trudov, 9, pp. 164-174.

Tompos, A. (2015). Austrian and Hungarian Values and Norms in Cross-Cultural Management Research. Impresa Progetto - Electronic Journal of Management, 12(3), Paper Tompos, 16 p. Available at:

https://www.impresaprogetto.it/sites/impresaprogetto.it/files/articles/2015_3_tompos.pdf [Accessed 11 Nov. 2019] 